\title{
A significação das estruturas formulares dos epimítios da fábula esópica anônima
}

\author{
MARIA CELESTE CONSOLIN DEZOTTI \\ Departamento de Linguística \\ Faculdade de Ciências e Letras \\ Universidade Estadual Paulista \\ Campus de Araraquara
}

RESUMO: Este trabalho apresenta os resultados da análise da organização textual das fábulas esópicas anônimas. O exame das marcas linguísticas que fazem a coesão textual dos dois textos constitutivos da fábula - a narrativa e o epimítio - mostrou que a fábula é um gênero discursivo que se configura como um tipo particular de ato de palavra realizado por meio de uma narrativa que se deve interpretar segundo as orientações de seu locutor. Nas fábulas de coleções anônimas, estas orientações se acham explicitadas lingüisticamente por verdadeiras fórmulas metalingüísticas, situadas, topicamente, no início do epimítio. Pode-se demonstrar o estatuto formular destas expressões metalingüísticas tanto pela sua constante repetição em um grande número de fábulas, como, e sobretudo, pela elevada freqüência das marcas de elipses nominais, verbais e oracionais que estas fórmulas apresentam. Observou-se, também, que a recuperação das unidades lexicais que completam os esquemas subjacentes às construções elípticas se torna possível somente se se recorrer a outras fábulas do corpus. Estes fatos nos permitem pressupor a existência de paradigmas de fórmulas acumuladas na competência lingüística do locutor e do ouvinte grego, do mesmo modo que nos revelam um engajamento da fábula esópica para assinalar lingüisticamente sua condição de enunciado.

PALAVRAS-CHAVE: Esopo, fábulas, epimítios, lingüística, literatura grega, Grécia.

\section{Fábula e discurso}

Grande parte dos estudos que se fizeram sobre a fábula esópica anônima, com vistas a descrever as características comuns aos textos que a tradição nos 
transmitiu sob o rótulo de Aisópou mŷthoi - Fábulas de Esopo, centra-se na análise dos textos narrativos que compōem tais fábulas ${ }^{1}$. Haja vista a variedade de tipos de narrativas que elas empregam, torna-se inviável, só pelo exame dessas estruturas narrativas, encontrar um denominador comum que justifique o agrupamento de tais textos numa mesma classe. Geralmente, constatada a variedade, acaba-se por excluir do gênero fábula os textos que por ventura se desviam do que cada analista estabelecera, previamente, como "fábula-padrāo".

O maior ou menor sucesso na descrição das fábulas esópicas anônimas depende, fundamentalmente, da relevância que se concede ao que já os antigos retores denominavam promýthium ou epimýthium ${ }^{2}$, termos com que eles nomeavam a moralidade da fábula, usando o primeiro se elà estivesse colocada antes do texto narrativo, e o segundo, caso ela viesse depois. Promítios são freqüentes nas fábulas de Fedro. Nas fábulas esópicas anônimas, porém, a moralidade vem sempre expressa em forma de epimítio.

Estudos recentes reconhecem, por meio de evidências lingüísticas, a "venerável antigüidade"do epimítio ${ }^{3}$. Contudo, ele não tem recebido a devida atenção como componente sistemático da fábula esópica. E por mais que se tente desconsiderar sua função constitutiva do gênero, uma hora ou outra a análise exige que se lance mão dele para explicar a condição de fábula de certos textos narrativos. Isto significa que a condição de fábula de um texto não se reduz à sua condição de narrativa. A fábula é mais que uma narrativa; ela é, antes de tudo, uma fala, como ela própria traz registrado em seu próprio nome - fábula $a^{4}-$, um Lógos, que se realiza por meio de uma narrativa, por meio de um mýthos ${ }^{5}$. Logo, o próprio ato de narrar está, na fábula, sobredeterminado por intenções comunicativas que governam qualquer ato de fala ${ }^{6}$.

S. Suleiman afirma que as "narrativas exemplares", entre as quais ela insere a fábula, sāo estruturadas com base em um verbo ilocutório: "demonstrar". E ela mostra que o funcionamento discursivo de tais narrativas se dá pela articulação de três discursos, dispostos hierarquicamente: um narrativo, inferior, um interpretativo e um pragmático, o mais alto da hierarquia, por meio do qual o destinador da fábula apresenta ao destinatário (leitor/ouvinte) uma injunção, extraída do discurso interpretativo.

A natureza ilocutória da fábula também foi apontada por A. D. Lima como um aspecto de seu funcionamento que ela deixa manifesto na moralidade. Esta, segundo Lima, não se constitui apenas de discurso interpretativo, como se está habituado a pensar; além do discurso interpretativo, a moralidade apresenta ainda um outro discurso, que Lima nomeia "metalingüístico", expresso por recursos de natureza segmental ou não, entre os quais se encontram as frases do tipo "a fábula mostra", "a fábula ensina". Esse discurso metalingüístico, além de promover a articulação da narrativa com a moral, permite que se recupere tanto a enunciação do discurso que a fábula é, como as marcas de seu enunciador e do valor ilocutório que ele confere à sua enunciação. "Não ler esse discurso, diz Lima, é no mínimo deixar incompleta a tarefa lingüística de análise do discurso pelo qual o texto da fábula se atualiza" (Lima, p. 64).

Nas fábulas esópicas, discursos interpretativos e discursos metalingüísticos se expressam em epimítios. Então, quando se trata de descrever a sua organização discursiva, é necessário que se dê ao epimítio o mesmo grau de relevância que se tem dado à narrativa, já que ele é o espaço onde as propriedades discursivas do gênero se explicitam por meio de enunciados lingüísticos. 
Considerando-se, pois, que o discurso metalingǘstico é a instância que funda um enunciado narrativo como.fábula, examinaram-se os epimítios das fábulas esópicas anônimas, para se detectar neles os enunciados metalingüísticos e descrever os expedientes de que eles se servem para estruturar esses enunciados.

\section{Estruturas discursivas do epimítio}

O exame de 348 fábulas mostra que os epimítios apresentam estruturas discursivas muito variadas ${ }^{7}$. Essa variedade fica evidente quando se tenta decompor os epimítios em duas porçóes de textos, correspondentes, uma, ao enunciado metalingǘstico, e outra, ao enunciado moral ou interpretativo. Para que tal decomposição seja possível, é necessário que o discurso moral esteja explícito, o que nem sempre acontece, como se mostrará a seguir.

Nesse procedimento de decomposição do epimítio em dois enunciados, considerou-se como enunciado moral a porçáo de texto do epimítio que, destacada do contexto, mantivesse autonomia significativa, como a que apresenta o epimítio seguinte:

Certas pessoas que são responsáveis pelos próprios males direcionam totalmente a censura à divindade. ( $\mathrm{Ch}$ 99)

Esse epimítio, que explicita apenas o discurso moral, constitui um caso singular na coletânea ${ }^{8}$. Retirado do contexto, ele poderia ser enunciado como se fosse uma máxima, sem prejuízo algum de seu significado.

Contudo, a grande maioria dos epimítios está elaborada de outro modo. Como se pode observar nos exemplos abaixo, muitos epimítios permitem que se isole do enunciado moral, uma outra porção de texto que não compōe seu significado. Enquanto o enunciado moral mantém sua autonomia significativa, a porção de texto isolada fica pendente ${ }^{9}$.

Assim (hoútos), a competição com os superiores, além de não levar a nada, ainda faz rir das infelicidades. (Ch .5)

Assim, também (hoúto kâ) certos homens que não conseguem realizar seus negócios por incapacidade, culpam as circunstâncias. (Ch 32)

O discurso mostra que (ho Lógos delô̂ hóti) muitos, por interesse particular, não hesitam de modo algum em dar falso testemunho de coisas impossíveis. (Ch 10).

Pois bem. Portanto, também (atdr oun kâ) nós é preciso que evitemos a amizade daqueles cuja postura é ambígua. (Ch 60).

Existe, porém, um segundo grupo de epimítios que apresenta outra estrutura discursiva. Em vez de explicitarem um enunciado moral, os epimítios desse grupo indicam um destinatário específico para a fábula, identificado como portador de algum tipo de falha moral. Em relação a esse destinatário, a quem a fábula reserva a tarefa de elaborar o discurso moral implícito, fazem-se diferentes predicaçōes ao texto narrativo. Vê-se, pois pelos exemplos que seguem abaixo, que esses epimítios são inteiramente metalingüisticos. 
O discurso é oportuno para (ho Lógos éukairós estin prós) um homem libertino que está perdido por causa da luxúria. (Ch 157)

Essa fábula recrimina (hoatos ho mŷthos elégkhei) os ambiciosos que passam a vida no fingimento e na presunção. (Ch 63)

Esse discurso uma pessoa pode usar em relação a (toúto tô Lógo khrésaito dn tis prós) um homem ladrão. (Ch 110)

Segundo esse critério de decomposição do epimítio, foi possível identificar vários tipos de textos que expressam o discurso metalingüístico da fábula anônima. Dispostos em quadros, como se vêem a seguir, cada tipo e suas variantes vêm acompanhados do seu número de ocorrências bem como do número de uma fábula de coletânea que pode ser consultada como exemplo. Os quadros de 1 a 5 contêm enunciados metalingüísticos que introduzem um discurso moral explícito; referemse, pois, ao primeiro grupo de epimítios, que foram apresentados como passíveis de serem decompostos em dois enunciados, um metalingüístico e um moral. Já os quadros de 6 a 12 contêm construções metalingüísticas dos epimítios que não trazem discurso moral explícito.

\section{Quadro 1}

\begin{tabular}{|l|c|l|}
\hline ho mŷthos delô̂ hóti & 51 & Ch 68 \\
ho Lógos delô̂ hóti & 67 & Ch 10 \\
ho Lógos delô̂ (+ infinitivo) & 1 & Ch 17 \\
ho Lógos delô̂ (+ nome) & 1 & Ch 226 \\
ho Lógos didáskei (+ nome) & 4 & Ch 4 \\
hoútos ho Lógos didáskei (+ infinitivo) & 1 & Ch 293 \\
didáskei hemas ho Lógos hóti & 1 & Ch 181 \\
\hline
\end{tabular}

Quadro 2

\begin{tabular}{|l|c|l|}
\hline hoútos & 47 & Ch 5 \\
hoútos kai & 35 & Ch 32 \\
hoútos kai (hemas) & 1 & Ch 202 \\
\hline
\end{tabular}

Quadro 3

\begin{tabular}{|l|c|l|}
\hline atàr oun kaì (hemâs) & 7 & Ch 60 \\
atàr oun kai (hemass) ho Lógos didáskei & 1 & Ch 356 \\
\hline
\end{tabular}

Quadro 4

\begin{tabular}{|l|l|l|}
\hline hóti & 63 & Ch 1 \\
\hline
\end{tabular}


Quadro 5

\begin{tabular}{|l|l|l|}
\hline horàs (hóson) & 1 & Ch 210 \\
\hline
\end{tabular}

Quadro 6

ho Lógos harmódios estin prós

ho Lógos eúkairos estin prós

ho Lógos eúkairos prós

ho Lógos harmózei prós

hoútos ho Lógos harmóttei prós

hoútos ho Lógos harmóseien án prós

hoútos ho Lógos harmóseien án ept

ho mŷthos harmózei en

\begin{tabular}{|c|c|}
\hline 1 & Ch 321 \\
\hline 1 & Ch 157 \\
\hline 18 & Ch 24 \\
\hline 2 & Ch 108 \\
\hline 1 & Ch 41 \\
\hline 2 & Ch 234 \\
\hline & Ch 164 \\
\hline 1 & Ch 144 \\
\hline
\end{tabular}

Quadro 7

ho Lógos eíretai pros

ho Lógos eiretai en

ho Lógos Lekhtheie án ept

hoútos ho Lógos Lekhthele an ept

hoútos ho Lógos eikótos an Légoito ept

\begin{tabular}{l|l}
\hline 2 & Ch 297 \\
1 & Ch 147 \\
3 & Ch 130 \\
1 & Ch 74 \\
1 & Ch 290 \\
\hline
\end{tabular}

Quadro 8

\begin{tabular}{|l|l|l|}
\hline ho Lógos prós & 1 & Ch 152 \\
ho mŷthos prós & 7 & Ch 330 \\
ho mŷthos pert & 1 & Ch 17 \\
ho mŷthos hoatos prós & 1 & Ch 292 \\
\hline
\end{tabular}

Quadro 9

toúto t Lógo khrésaito àn tis prós

toúto t khrésaito àn tis epi

\begin{tabular}{l|l}
\hline 8 & Ch 110 \\
1 & Ch 65 \\
\hline
\end{tabular}

Quadro 10

\begin{tabular}{|l|l|l|}
\hline $\begin{array}{l}\text { toûto eikótos eípoi àn tis prós } \\
\text { touto páskhousin hoi (+ particípio) }\end{array}$ & 1 & Ch 340 \\
\hline
\end{tabular}

Quadro 11

\begin{tabular}{|l|l|l|}
\hline prós & 4 & Ch 115 \\
\hline
\end{tabular}


Quadro 12

\begin{tabular}{|l|l|l|}
\hline ho mŷthos elégkhei & 5 & $\mathrm{Ch} 345$ \\
hoútos ho mŷthos elégkhei & 1 & $\mathrm{Ch} 63$ \\
ho parón mŷthos steliteúei & 1 & $\mathrm{Ch} 133$ \\
\hline
\end{tabular}

O exame dos quadros anteriores mostra que os epimítios das fábulas esópicas se estruturam, permanentemente, com enunciado metalingǘstico. Se o enunciado moral pôde não se explicitar em 67 epimítios, o enunciado metalingüístico, por sua vez, está presente em todos.

Nota-se, também, que o fato de existirem 281 epimítios compostos com os dois enunciados, mostra que são predominantes, na coletânea, fábulas que realizam os três discursos constitutivos do gênero, apontados por A. D.Lima.

Além disso, é fácil observar que os enunciados metalingüísticos se expressam por construçōes lingüísticas recorrentes, que devem ser consideradas como verdadeiras fórmulas de natureza metalingüística ${ }^{10}$. Observa-se, ainda, que elas tendem, muito significativamente, a ocupar a posição inicial do epimítio.

\section{A natureza coesiva das fórmulas metalingüísticas}

As fábulas anônimas se caracterizam por expressar, como ficou apontado, enunciados narrativos e enunciados metalingüísticos, podendo ou não explicitar-se o enunciado moral. Cada um desses enunciados se concretiza em textos, resultando, pois, da articulação deles o texto maior da fábula, que, como todo e qualquer texto completo, constitui uma "unidade semântica" (HALLIDAY; HASAN, p. 2). Isto implica que não se deve buscar entre as frases que realizam esses diferentes enunciados as mesmas relações estruturais de natureza sintática, que se verificam entre as oraçōes que compōem uma frase ${ }^{11}$. Entre o texto da narrativa e a frase que realiza o texto do epimítio existem, isto sim, relações semânticas, de natureza interfrasal, que conferem ao texto maior a condição de todo coeso.

Dada a relevância que o enunciado metalingüístico demonstra ter na estruturação do texto da fábula, procurou-se identificar que marcas lingüísticas de coesão textual ele contém, que lhe permitem desempenhar o papel de articulador do texto, uma vez que ele, a um só tempo, instaura relações coesivas com o enunciado narrativo, e promove a coesão desse enunciado com o enunciado móral.

Examinaram-se, então, as fórmulas metalingüísticas para se identificar quais seriam os itens lingüísticos que elas usam para estabelecer os tais elos coesivos. $O$ isolamento daqueles itens, por sua vez, mostrou que a fábula seleciona, para atuar nas fórmulas metalingüísticas, quatro tipos de elos: a referência, a coesão lexical, a conjunção e a elipse (HALLIDAY; HASAN). Ver-se-á, a seguir, que cada um desses tipos se expressam por variados expedientes lingüísticos. 


\subsection{Referência e coeso lexical: ho Lógos e ho mŷthos}

O princípio da referência, aliado ao da coesão lexical, constitui o expediente coesivo predominante nas fórmulas metalingüísticas, estando presente, pois, em 187 epimítios.

A coesão lexical se opera por meio dos nomes gerais Lógos e mŷthos, cujo estatuto metalingüístico é facilmente apreendido em vista de tais termos serem nomes de "enunciados lingüísticos". Modificados pelo artigo definido, ao qual se junta, algumas vezes, uma forma demonstrativa (hoûtos), aqueles nomes entram na composição de sintagmas que instauram referência anafórica. Por meio da anáfora, os nomes Lógos e mýthos fazem pressupor que seus referentes existem e que constituem informaçōes encontráveis na porção precedente do texto. Esta corresponde, na fábula, ao texto narrativo. Nota-se, porém, que o referente de ho lógos e de ho mŷthos não será uma pessoa ou coisa mencionada no texto narrativo, mas será o próprio texto narrativo, como um só enunciado, em sua totalidade.

\subsection{Referência: toûto}

Duas fábulas da coletânea apresentam epimítio introduzido pelo demonstrativo toûto ("isso"), mas o seu comportamento semântico difere nos dois textos.

Em Ch 33, narra-se o caso de uma raposa que, invejando o tamanho de uma cobra, desejou igualar-se a ela e, para isso, foi-se esticando tanto que acabou se rebentando. Segue-se, então, o epimítio:

Isso (toûto) sofrem os que lutam contra os superiores; é que eles próprios se arrebentam antes de conseguir atingi-los.

Enquanto item de referência demonstrativa, o pronome toûto aponta para a porção final do texto narrativo que o precede, e com a qual ele mantém relação de proximidade. Nota-se, porém, que nesse epimítio o demonstrativo toûto constitui o núcleo do sintagma. Ora, quando um demonstrativo ocupa a posição de núcleo, a referência que ele instaura pode ampliar-se à classe geral referida pelo item que ele pressupõe. Assim, o pronome toûto, e também o pronome "isso" que o traduz, retoma não apenas o arrebentar-se da raposa relatado no texto narrativo, mas também o "arrebentar-se em geral" que ocorre com os que ousam competir com os superiores.

Já em Ch 340 , a referência que o pronome toûto estabelece incide sobre o aspecto discursivo do texto narrativo, e não sobre seu conteúdo. Veja-se o texto dessa fábula:

Dizem que as hienas mudam de natureza de ano em ano, tornando-se ora machos, ora fêmeas. E assim, certa vez uma hiena macho se comportou, com uma hiena fêmea, de modo contrário à sua natureza. Entāo ela tomou a palavra e disse: "Mas faça isso mesmo, meu caro, que logo a tratamento idêntico você vai se sujeitar."

Isso (toûto) pode dizer, com razão, em relação à que já está governando, uma pessoa que está para sucedê-la, caso recebesse, da parte dela, um desaforo. 
Vê-se que o pronome touto, nesse epimítio, complementa uma forma do verbo Légo ("dizer"), que pressupõe como complemento um enunciado. Sendo o pronome esse complemento, ele deve, necessariamente, referir-se a um enunciado. $O$ texto narrativo que precede o epimítio oferece duas alternativas que podem funcionar como referentes do pronome: uma delas $\varepsilon$ o enunciado que a hiena fêmea dirige à hiena macho, encerrando a narrativa; a outra é o próprio texto narrativo, que também constitui um enunciado. É que tanto a fala da hiena fêmea, como a própria narrativa sobre as hienas são adequadas para a situação prevista pelo epimítio.

Tanto num caso como no outro, a referência que o pronome toato estabelece é de natureza metalingüística, pois o seu referente é, de qualquer modo, um enunciado, seja ele retomado quanto ao seu conteúdo, como em $\mathrm{Ch} 33$, seja ele retomado quanto à sua forma, como em Ch 340 .

\subsection{Conjunção}

A conjunção constitui o segundo tipo de relação coesiva mais usado nos epimítios das fábulas anônimas. Ela se realiza por meio de três diferentes fórmulas metalingǘsticas, sendo as duas primeiras que a seguir se apresentam, muito recorrentes, e a última, muito rara, embora seja extremamente valiosa para o estudo da história do epimítio.

\subsubsection{O valor conclusivo de hoútos}

O advérbio hoútos ("assim") aparece no início de 83 epimítios, mas a descrição de seu comportamento sintático nesse conjunto mostra que na realidade, ele deve ser interpretado de dois modos diferentes, de acordo com a estrutura sintática em que ele se encaixa. Há epimítios em que hoútos vem imediantamente seguido de nominativo + genitivo, como ocorre, por exemplo, em Ch 196: hoútos hoi poneroi tôn anthrópon ("assim, os homens perversos"); em outros, ele vem seguido de kat + genitivo + nominativo, como em Ch 8: hoútos kal tôn anthrópon hoi ponerol ("assim, também os homens perversos"). Essas duas diferente estruturas sintáticas correspondem a duas diferentes fórmulas, expressas pelo mesmo item gramatical. No primeiro caso, ele instaura, entre o epimítio e a narrativa, uma relação coesiva de natureza causal; no segundo, de natureza comparativa, como se verá mais adiante.

Veja-se a fábula "Zeus e Apolo" (Ch 121):

Zeus e Apolo disputavam a arte de manejar o arco. Após Apolo ter retesado o arco e lançado o dardo, Zeus esticou uma perna até o ponto que Apolo havia atingido.

Assim (hoútos), os que competem com os superiores, além de não sobrepujá-los, ainda se expōem ào riso.

O enunciado moral dessa fábula seleciona, da narrativa, a sequência de fatos vivenciados por Apolo e a reitera como sequência de fatos virtuais em relação a 
qualquer ser humano que, como ele, ousa competir com seus superiores. Trata-se, pois, de uma generalização do particular para o geral, de modo que o conteúdo do texto moral abrange o conteúdo do texto narrativo.

Essa relação de inclusão que se estabelece entre narrativa e moral confere ao advérbio hoútos um valor conclusivo, explicitando-se, por meio dele, a condição de conclusão, que caracteriza o texto moral, extraída do texto narrativo.

\title{
3.3.2. O valor comparativo de hoútos kai
}

\author{
Veja-se, agora, a fábula "O orador Demades" (Ch 96)
}

O orador Demades falava, certa vez, ao povo de Atenas. E como eles não lhe prestavam atençāo de jeito nenhum, pediu-lhes permissão para contar uma fábula esópica. Tendo eles consentido, começou a dizer: "Uma andorinha, uma enguia e Deméter seguiam por um mesmo caminho. Quando chegaram a um rio, a andorinha voou e a enguia mergulhou."Disse isso e calou-se. Então eles perguntaram: "E Deméter? O que aconteceu com ela? Aí ele respondeu: "Ela está bronqueada com vocês, que deixaram de lado os assuntos da cidade para se ligar em fábulas esópicas."

Assim, também (hoútos kaí) dentre os homens, são irracionais os que negligenciam os afazeres necessários e dão preferência às coisas prazerosas.

Verifica-se, nessa fábula, que a formula "assim, também "estabelece, entre a narrativa e a moral, uma relação semântica de natureza comparativa. Nessa relação coesiva, cada um dos itens que compõem a fórmula privilegia um aspecto diferente dos textos que eles articulam. $O$ advérbio hoútos ("assim"). faz a coesão dos dois textos enquanto enunciados potencialmente comparáveis num dado contexto. Trata-se, então, de uma conexão semântica de natureza discursiva, que privilegia os enunciados como etapas constitutivas de um processo de interação comunicativa (HALLIDAY; HASAN, p. 241). A partícula kal ("também"), por sua vez, completa aquela conexão semântica instaurada pelo advérbio, na medida em que incide sobre o conteúdo dos dois enunciados, apresentando-os como conteúdos passíveis de comparação, embora cada um deles organizem diferentes mundos referenciais.

Só assim é que: se pode explicar a comparação de uma narrativa que fale de "homens", os atenienses, no caso, com uma moral que também fale de "homens". E que o texto narrativo deve ser considerado um enunciado ficcional, que instaura seu próprio mundo de referências. Deve-se, pois, considerá-lo uma "realidade lingüística", constituída pela palavra, que narra fatos sobre os quais não se colọca em questão se eles acontecem ou não, no mundo extralingüístico. $O$ mesmo não se pode dizer do texto moral, pois este faz asserçōes a respeito de entidades do mundo extralingüístico, o mundo das relações humanas, para o qual remete a natureza exofórica do artigo definido que forma a expressão "dentre os homens" (tôn anthrópon).

Observa-se, entāo, que o advérbio houtos, tenha valor conclusivo, tenha valor comparativo, funciona, nas fórmulas introdutoras de epimítios, como expediente coesivo de natureza metalingüística, pois ele fundamenta a conexāo semântica que 
opera entre o epimítio e a narrativa sobre a condição de enunciado, de produto discursivo, que eles são.

\subsubsection{O complexo atàr oûn kaí}

Usada como fórmula introdutora de epimítio em oito fábulas anônimas ( $\mathrm{Ch}$ $23,53,60,163,245,272,284,356$ ), a expressāo atàr oûn kaí ("Pois bem. Portanto, também") acumula três itens gramaticais conferidores de coesão entre o texto narrativo e o epimítio.

Ela aparece, por exemplo, na fábula "O homem e o sátiro" (Ch 60), que se reproduz a seguir.

Conta-se que, certa vez, um homem firmou um pacto de amizade com um sátiro. E aí, quando sobreveio o inverno e chegou o frio, o homem levava as mãos à boca e soprava. Como o sátiro lhe perguntasse o motivo pelo qual fazia aquilo, disse que estava aquecendo as mãos por causa do frio. Mais tarde foi-lhes servida a mesa e, como a comida estivesse muito quente, o homem tomava uma pequena porção, levava-a à boca e soprava. Quando o sátiro the perguntou de novo por que ele fazia aquilo, ele disse que estava esfriando o alimento, pois estava quente demais. Então aquele lhe disse: "Só que dispenso sua amizade, meu caro, pois da mesma boca você lança tanto o frio como o calor."

Pois bem. Portanto, também (atàr oûn kaí) nós é preciso que evitemos a amizade daqueles cuja poştura é ambígua.

A interpretação dos valores semânticos de cada um dos itens que compōem a fórmula atàr oûn kai - que na tradução acima equivale a "Pois bem. Portanto, também" - incide sobre diferentes âmbitos do texto. Nota-se que a forma "também" (kaí) incide sobre o pronome "nós"; a conjunção "Portanto" (oûn) incide sobre o enunciado moral como um todo, e a forma "Pois bem" (atár) incide sobre a própria enunciação do período. Ver-se-á que cada um desses itens estabelece um tipo diferente de relação coesiva.

Usada na fórmula com valor comparativo, a partícula kai estabelece um ponto de igualdade entre duas realidades diferentes. Contrasta-se, por meio dela, um nós, do texto moral, com um não-nós, representado no texto narrativo pela figura do sátiro, cujo comportamento se mostra modelar.

A conjunção oûn, por sua vez, tem valor conclusivo, conferindo ao enunciado moral a condição de "etapa seguinte" de um processo argumentativo que se iniciou com a enunciação de uma narrativa. Tem-se, portanto, umá conclusão que se especifica em forma comparativa.

Já a partícula atár tem um funcionamento mais complexo. Aliás, o seu valor semântico só pode ser determinado pela análise de suas ocorrências fora do conjunto das fábulas anônimas.

Adrados (ADRADOS, Estudio..., p. 236) nota que essa partícula ocorre na Retórica de Aristóteles, especificamente num texto de Esopo que Aristóteles cita em discurso direto. Trata-se da fábula que Esopo teria pronunciado ao povo de Samos, quando se estava acusando de crime capital um demagogo. Esopo, segundo 
Aristóteles (Arte Retórica, 1393 b), teria encerrado sua narrativa sobre a raposa que fora atacada por um grande número de carrapatos, com o seguinte epimítio:

Poị bem. Também (atdr kal) a vocês, homens de Samos, esse demagogo em nada mais vai prejudicar (pois está rico), mas se o matarem, virão outros, pobres, que vão lhes roubar e dilapidar o restante dos bens.

As informaçōes de Aristóteles fazem pressupor que a fábula de Esopo se realiza num contexto maior em que ele discorria a respeito das vantagens ou desvantagens de se acusar o demagogo naquele momento. Pressupōe-se, então, que ele tenha interrompido suas consideraçōes para introduzir a narrativa sobre o caso da raposa. Finda a narração, ele enuncia o epimítio. A partícula atán marca exatamente essa passagem do nível narrativo para o nível argumentativo, ancorando o enunciado narrativo na situação em que ele foi produzido, e anunciando que se vai apresentar, em seguida, uma justificativa para o fato de ele ter sido produzido naquela situação. Assim, essa partícula nāo só torna coesos o texto narrativo e o epimítio, como também confere à fábula inteira a condição de texto adequado àquela situação.

Essas constatações orientam a interpretar a partícula atár nos epimítios das fábulas anônimas, como uma marca da condição oral da fábula, preservada no texto escrito. Pode-se mesmo supor, que, no início de sua história, o epimítio fosse estruturado com partículas próprias da fábula enquanto prática oral, vinculada a uma dada situação discursiva. Só depois é que se processariam alterações com a finalidade de se eliminarem do texto as marcas da oralidade e lhe conferir o estatuto de texto escrito autônomo, desvinculado de uma situação particular ${ }^{12}$.

\subsection{Elipse}

Elipse é a omissão de algum item da estrutura de sintagmas ou de oraçōes. Essa omissão é feita de tal modo que deixa "pegadas" que favorecem a recuperação, no contexto, do item elíptico (HALLIDAY; HASAN, p. 143). Deve-se considerar, portanto, que a elipse se define em relaçāo a uma "norma", representada pelo "esquema canônico" que a estrutura completa preenche (CHERCHI, p. 118-128). Nos epimítios das fábulas anônimas encontram-se vários tipos de itens omitidos, que podem fazer parte de sintagmas nominais, verbais ou de oraçōes.

A elipse oracional constitui o tipo mais freqüente. São 63 ocorrências, e todas em fábulas extraídas da Paráfrase Bodleiana ${ }^{13}$. O marcador lingüístico da elipse oracional é a conjunção hóti ("que"), tal como aparece no início do epimítio seguinte, extraído de $\mathrm{Ch}$ 1:

[Que] ([hóti]) com bens ninguém depara rápido, mas pelos males cada pessoa é a cada passo atingida.

E interessante observar que se fosse suprimida do epimítio a conjunção $h \delta t i$, ele ficaria reduzido à mera expressão do texto moral. Por outro lado, fica evidente que essa conjunção tem a função de indicar que o epimítio, tal qual ele se apresenta, não está completo; ela marca que é necessário recuperarem-se os itens elípticos que tornariam completa a sua estrutura. 
A conjunção hóti indica que o texto moral que a segue deve ser tomado como oração completiva, que se articula, sintaticamente, a uma oração principal. Ora, é justamente essa oração principal que está elíptica. $O$ problema é que ela não se encontra nem na porção de texto precedente, nem na porção seguinte. Em suma, ela não se encontra "disponível" no contexto.

Em nossa condição de leitores modernos, podemos recuperar essa oração, necessária para preencher o esquema, em outras fábulas da coletânea que apresentam epimítios estruturados sintaticamente por oração principal acompanhada de completiva introduzida por hóti. Assim, podem-se citar como opçōes para preencher a elipse oracional, três das fórmulas apresentadas no Quadro 1, citado anteriormente. Tanto poderia ser ho lógos ou ho mŷthos delô̂ ("o discurso" ou "a fábula mostra"), como didáskei hemás ho lógos ("o discurso nos ensina"). Essas alternativas constituem, pois, três possíveis "esquemas canônicos" em função dos quais a elipse oracional marcada por hóti se realiza.

Vista, porém, da perspectiva do leitor grego, a recuperação dessa oração elíptica tem que ser colocada de outro modo. Esse leitor não precisava, como nós, recorrer às outras fábulas da coletânea, que apresentam o esquema completo, para recuperar itens elípticos. Com certeza ele os recuperava em sua própria memória, onde deviam estar estocados entre os procedimentos discursivos que constituíam sua competência discursiva, paradigmas de construção de epimíticos. Entre esses paradigmas estariam as fórmulas metalingüísticas.

Encontram-se na coletânea alguns casos de epimítios introduzidos por hóti em que essa conjunção não está convenientemente integrada à estrutura sintática do texto. É o que se observa em epimítios como o de Ch 345 , citado a seguir:

[Que] ([hóti]) Os dorminhocos e preguiçosos que até do esforço alheio se alimentam, a fábula censura.

Embora registrado entre colchetes, o emprego de hóti não se ajusta nesse epimítio por lhe conferir o estatuto sintático de oração completiva, em total desacordo com a condição sintática de oração absoluta que o epimítio apresenta.

O interessante é que, assim como Ch 345, os outros epimítios (Ch 93, 133 e 227) que vêm introduzidos inadequadamente por hóti apresentam suas fórmulas metalingüísticas deslocadas para a posição final do epimítio. Nesse deslocamento poderia estar a explicação para aquela inadequação.

A tendência dominante na coletânea é o uso da fórmula no início do epimítio. É possível que, quando a fórmula se encontra em posição final, o epimítio se mostrasse, à primeira vista, constituído só de texto moral, o que teria levado alguém, em algum momento, a completar sua estrutura discursiva, acrescentando um marcador de elipse, por meio do qual se faria recuperar uma fórmula metalingüística.

Esses fatos permitem supor que havia uma, certa resistência em se aceitar epimítio que só explicitasse o texto moral. $O$ fato de se acrescentar ao epimítio a conjunção hóti permite concluir, por outro lado, que as fórmulas metalingüísticas expressas pelas oraçōes que aquela conjunção pressupōe, já deveriam estar consagradas pelo uso, bastando, pois, um simples marcador de elipse para integrá-las à estrutura do epimítio.

O mesmo processo de recuperação, fora do texto da fábula, de itens elípticos vale também para as elipses nominais e verbais. 
O tipo mais freqüente de elipse verbal é o que ocorre na fórmula ho lógos éukainos prós ("o discurso, oportuno para"), que apresenta elíptica a forma verbal estin ("é"). Aliás, como se pode observar no Quadro 6, o esquema canônico dessa construção aparece uma única vez na coletânea.

São menos freqüentes os casos de elipses marcadas pela preposição prós. Elas ocorrem nas estruturas ho lógos/mŷthos prós ("o discurso/fábula para"). Tais elipses supõem várias alternativas de itens recuperáveis, pois aquelas estruturas podem se completar com qualquer dos sintagmas verbais que regem prós + acusativo, dentre as alternativas mencionadas nos Quadros 6 e 7.

Já a elipse marcada por prós é a que conta com o maior número de alternativas para preencher seu esquema canônico. Um epimítio como o de Ch 115, que diz:

Para (prós) homem perverso que empreende tarefas penosas.

pode se completar com qualquer estrutura de que participe prós +acusativo, dentre as citadas nos Quadros 6, 7 e 8 ou nos Quadros 9 e 10.

Como observação geral a respeito do uso de fórmulas com construçōes elípticas nas fábulas anônimas, importa ressaltar que o emprego de marcadores de elipses como a conjunção hóti e a preposição prós representa o expediente mais econômico possível para se deixar indicada, na estrutura do epimítio, a existência de um discurso metalingüístico, pois os itens lexicais lógos ou mŷthos se encontram presentes em qualquer dos esquemas recuperados. Por meio da elipse, registra-se, economicamente, uma intenção de se organizar o texto da fábula de tal modo que se possa ostentar a condição de discurso, que ela $e$.

\subsection{Um caso particular: Ch 210}

Trata-se da fábula "O leão, Prometeu e o elefante" (Ch 210), que narra a história de um leão desesperado por ter medo do galo. Embora Prometeu, seu criador, procurasse consolá-lo, ele só se conforma com sua fraqueza quando descobre que o elefante recuava diante do mosquito, um animal muito menor que o galo. E encerra com o seguinte epimítio:

Você está vendo quanta força tem o mosquito, a ponto de amedrontar até um elèfante.

O que se vê, nesse epimítio, é que o enunciado metalingüístico está representado exatamente pela expressão "Você está vendo", com que se traduziu a segunda pessoa do singular do Verbo horáo ("ver").

A forma verbal, nesse caso horás, estabelece uma relação coesiva de tipo lexical entre o enunciado narrativo e o enunciado moral de um modo muito particular: em vez de focalizar a produção do discurso, como fazem os outros itens coesivos já analisados, ela focaliza o ato de fala do ponto de vista de sua recepçäo por parte do ouvinte/leitor da fábula. Afinal, ver nada mais é, em se tratando de um epimítio de fábula, que o processo resultante de um pressuposto ato de mostrar; que, é necessário ter sempre em vista, constitui o ato verbal explicitado na fórmula metalingüistica mais reiterada na coletânea: "o discurso / a fábula mostra": 


\section{O estatuto paradigmático do epimítio}

As fábulas anônimas documentam, como se pôde verificar, várias alternativas de expressão lingüistica do enunciado metalingüístico. Este pode explicitar-se por meio do vocabulário, através de itens lexicais como Lógos e mŷtos, que se referem ao texto narrativo enquanto entidade lingülstica, ou por meio da gramática, através de itens demosntrativos e conjuntivos que realizam sua ação coesiva mediante a pressuposição de que os enunciados que eles relacionam contituem eventos lingüísticos.

Por outro lado, o exame e a interpretação que se fizeram das marcas coesivas presentes nas fórmulas metalingüísticas permitem concluir que a fábula, ao optar por realizar, entre o texto narrativo e o epimítio, relações coesivas de natureza discursiva, se caracteriza como um texto que se organiza de modo a escancarar a sua condição de enunciado, de discurso. E reserva, para confessar sua identidade, um espaço bem delimitado o início do epimítio.

O dado que melhor comprova esse empenho do texto são as elipses. Elas significam, em última análise, uma recusa, por parte do locutor da fábula, em compor seu texto sem metalinguagem.

Além disso, o uso da elipse como fator coesivo mostra que as fórmulas metalingüísticas já constituíam um paradigma estocado na competência discursiva do falante grego, que deve ser visto como o legítimo destinatário das fábulas gregas. Esse fato obriga que se veja a fábula anônima como documento de um estágio da história da fábula esópica em que esta já se encontrava fixada como tipo discursivo composto de texto narrativo $e$ de epimítio. Afinal, o estilo formular e as construções elípticas constituem provas de que o epimítio esteve, necessariamente, sempre presente nesse processo de fixação do gênero "fábula", como sua parte integrante.

\section{Notas}

1- Ver; por exemplo, PERRY; NOJGAARD; GASPAROV.

2- Promythium aparece, pela primeira vez, em Aftônio (séc. V) e epimythium, em Luciano (séc. II). Cf. NOJGAARD, p. 121. Dada a frquência com que esses termos serāo usados neste estudo, optou-se pelo aportuguesamento dos termos latinos em promitio e epimitio, respectivamente.

3- Cf. NOJGAARD, p. 236; ADRADOS, 1948; CHAMBRY, 1967.

4- O termo fábula é um derivado de "fari", "falar". Cf. BENVENISTE, "Fas".

5- Resgata-se, assim, o alcance da primeira definição de fábula que se conhece, formulada por Teon, retor do séc. I: mŷthos esti Lógos pseudès eikonizon alétheian (apud NOJGAARD, p. 55). Quanto à delimitação do sentido de "mito" como "narrativa", ver VERNANT, p. 196-210.

6- ADRADOS (ADRADOS, 1982, p. 33-36) propõe que os promítios e os epimítios surgem como uma solução que a fábula, já na condição' de texto escrito, encontra para explicitar uma intenção comunicativa que, na prática oral, podia ser recuperada pelo ouvinte no contexto de sua enunciação. 
7- A Edição consultada é a de CHAMBRY, o.c., que abriga 358 fábulas, das quais dez, apenas, são estruturadas sem epimítio.

8- Tem-se aí um caso de ocorrência de discurso metalingüístico de natureza suprassegmental, prevendo-se, pois, na enunciação do epimítio, uma mudança de tom, para mais baixo. Cf. LIMA, p. 64.

9- Grifou-se, nesses epimítios, a porção de texto correspondente ao discurso metalingüístico.

10- ADRADOS (ADRADOS, 1978) observa que o próprio texto narrativo das fábulas, sobretudo das fábulas da coleção Augustana, a mais antiga que nos chegou, apresenta um verdadeiro estilo formular.

11- Equívocos dessa natureza é que levam Nojgaard, p. 54, a afirmar que entre o epimítio da fábula e o texto narrativo nāo há ligação nem mesmo de natureza gramatical.

12- Que as expressōes lexicais como "ho logos" e "ho mŷthos" vão se sobrepondo às gramaticais, provam as fórmulas que introduzem o epimítio de $\mathrm{Ch} 356$, apresentadas no Quadro 3.

13- NOJGAARD, p. 364. Trata-se de uma coleção de fábulas que constituem paráfrases em prosa das fábulas de Babrius, fabulista do século II.

\section{Referências Bibliográficas}

ADRADOS, F. R. Estudio sobre el léxico de las fábulas esopicas (en torno a los problemas de la koiné literária. Salamanca: Consejo Superior de Investigaciones Cientificas, 1948 (Theses et Studia Philologica Salmanticencia II).

ADRADOS, F. R. Prolegomenos al studio de la fabula en epoca helenistica. Emerita. Revista de Lingülstica y Filología Cláśsica, Madrid, 1978, XLVI, p. 1-81.

ADRADOS, F. R. La Fabula griega como genero literario. In: DELGADO, J.A.F. (ed.) Estudios de forma y contenudo sobre los generos literarios griegos. Cáceres; Universidad de Extremadura, 1982, p. 33-46.

ADRADOS, F. R. Les collections de fables à l'époque hellénistique et romaine. In: La Fable, V. Entretiens sur l'Antiquité Classique. Genève: Fondation Hardt, 1984, p. 138-195.

ARISTOTE. Rhétorique. Texte établi et traduit par M. Dufour et A. Wartelle. Paris: Les Belles Lettres, 1973.

AUSTIN, J. L. Quand dire, c'est faire. Paris: Seuil, 1970.

BENVENISTE, E. "Fas". Le Vocabulaire des Institutions Indo-Européenes v.2 Paris: Minuit, pp. 133-142.

CHERCHI, L. Léllipse comme facteur de cohèrence. Langue Française: Paris 38, 118-128, 1978.

DENNISTON, J. D. The Greek Particles. Oxford: Clarendon Press, 1966.

ESOPE. Fables. Texte établi et traduit par E. Chambry, $3^{\text {eme }}$ tirage, Paris: Les Belles Lettres, 1967.

GASPAROV, M. L. O tema e a ideologia das fábulas de Esopo. (em russo). Vestnik Drevnej Istorei. Moskva, 1968, 105:116-127.

HALLIDAY, M. A. K.; HASAN, R. Cohesion in English. London: Longman, 1976.

KOCH, I. G. V. Argumentação e Linguagem. São Paulo: Cortez, 1984. 
LIMA, A. D. A forma de fábula. Significação. Revista Brasileira de Semiótica. Araraquara, 4, 60-69, 1984.

NOJGAARD, M. La Fable Antique, v.1. Copenhague: Nyt Nordish Forlag, 1964.

PERRY, B. E. Babrius and Phaedrus. London: Heineman, 1975 (Loeb Classical Library).

SULEIMAN, S. Les récit exemplaire. Parabole, fable, roman à these. Poétique. Paris, 32, 468-489, 1977.

VERNANT, J-P. Mythe et société en Grèce Ancienne. Paris: F. Maspero, 1974.

CONSOLIN DEZOTTI, M. C. La signification des structures formulaires des epimythia de la fable ésopique anonyme. Classica, São Paulo, 5/6: 113-128, 1992/1993.

RÉSUMÉ: Ce travail présente les résultats de l'analyse de l'organisation textuelle des fables ésopiques anonymes. L'examen des marques linguistiques qui font la cohésion textuelle des deux textes constitutifs de la fable - la narrative et l'epimythium - a montré que la fable est un genre discursif qui se configure comme un type particulier d'acte de parole realisé au moyen d'une narrative qu'on doit intérpreter selon les orientations de son locuteur. Dans les fables des collections anonymes, ces orientations se trouvent explicitées linguistiquement par des veritables formules métalinguistiques, situées, topiquement, dans le début de l'epimythium. On peut démontrer le statut formulaire de ces expressions métalinguistiques tant par leur constante répétition dans un grand nombre des fables, comme, et surtout, par la fréquence élevée des marques d'élipses nominaux, verbaux et orationelles qui ces formules présentent. On a observé, aussi, que la récuperation des unités lexicales qui complètent les schémas sousjacents aux constructions éliptiques devient possible seulement si l'on recourt à d'autres fables du corpus. Ces faits nous permettent de présuposer l'existence de paradigmes de formules accumulés dans la compétence linguistique du locuteur et de l'auditeur grec, de même qu'ils nous révèlent un engagement de la fable ésopique pour signaler linguistiquement sa condition d'énoncé.

MOTS CLÉS: Ésope, fables, epimythia, linguistique, littérature grecque, Grèce. 